\title{
LA INSTRUMENTALIZACIÓN DE LA UNIVERSIDAD: PERSPECTIVAS Y CRÍTICAS*
}

\author{
Nicolás López PÉreZ** \\ Universidad de Chile, Chile \\ magonios@gmail.com
}

\begin{abstract}
"Muchos jóvenes reclaman extrañamente ser 'motivados', piden más cursos, más formación permanente: a ellos corresponde descubrir para qué se los usa, como sus mayores descubrieron no sin esfuerzo la finalidad de las disciplinas."

Giles Deleuze - Postdata sobre las sociedades de control (1990)
\end{abstract}

\begin{abstract}
RESUMEN: Alrededor de las conversaciones acerca de qué Universidad queremos y cuál es la que tenemos, surgen razones para realizar un análisis en la línea de esas interrogantes. Pasando, en primer lugar por el contexto histórico que sirve a modo de arqueología del concepto y como este ha ido mutando al calor de los vientos erosionadores de la historia. Necesario es también, caracterizar a la sociedad de manera crítica para afirmar de mejor manera el tema de la "instrumentalización" de la Universidad, de cómo se ha ido desviando de su fin primigenio. Luego, un par de reflexiones acerca de la Universidad y una de las causas principales que la historia ha arrojado respecto de su actualidad. De esa forma, intento atisbar el "hoy" de la Universidad.
\end{abstract}

Palabras clave: Universidad, instrumento, fin, conocimiento, critica, utilidad, riqueza.

\section{THE INSTRUMENTALIZATION OF THE UNIVERSITY: VIEWS AND CRITICS}

\begin{abstract}
Around the conversations about what University we want and which we have, appears reasons to make an analysis in the course of these questions. Passing, in first term by the historic context useful in kind of concept's archaeology and how this has been mutating at the heat of the erosion winds of the history. Necessary is too, characterize the society in a critic view to affirm in a better way the topic of the
\end{abstract}

\footnotetext{
Trabajo recibido el 2 de mayo y aprobado el 29 de mayo de 2012.

** Estudiante de séptimo semestre de Licenciatura en Ciencias Jurídicas y Sociales, Universidad de Chile. Ayudante ad honorem de las cátedras de Filosofía (de la) Moral, Historia de la Filosofía del Derecho e Introducción al Derecho.
} 


\begin{abstract}
"instrumentalization" of the University, of how it has been swerving of its "first endaim". Then, a couple of reflections about the University and one of the main causes who history has flung related to its actuality. In this way, I try to pry the "today" of the University.
\end{abstract}

Keywords: University, instrument, end-aim, knowledge, critic, utility, wealth.

\title{
1. PRESENTACIÓN
}

Acerca de la Universidad, ¿De qué hablar? ¿Su esencia? ¿Su finalidad? ¿El por qué surgió? -Claramente es un tema extenso del que saldrían muchísimas tesis de grado, controversias científico- epistemológicas y cualquier otro escenario que de lugar al diálogo de distintos entendimientos de las cosas. Sin perjuicio de lo anterior, en estas líneas pretendo trastocar el tema de instrumentalización de la Universidad (sí, acotando un poco el debate y la bibliografía). Confieso que en principio, me quería referir a la "esencia" de la Universidad, a propósito de lo que señalaba Jorge Millas ${ }^{1}$. Sin embargo, bien creí que sería una empresa demasiado ambiciosa. Lo mismo me pasó con la pregunta por el "fin" de la universidad (esto, no referido en términos fukuyamicos, sino que teleológicos). Aunque, lo anterior suele estar condicionado por cientos de estereotipos y un rango amplísimo de respuestas diferentes. Esto último se da por el carácter abierto -y humano ${ }^{2}$ - de la pregunta, existen muchas respuestas con cualidad de verdad relativa. En estos términos nunca una verdad absoluta categórica y apodíctica. Ahora bien, el tema de la Universidad como un instrumento para gestar doxas en la comunidad interesada en la búsqueda de la verdad, esto a propósito de sus orígenes, su historia, las circunstancias concomitantes que han penetrado en el contexto de la definición de dicha calidad y lo que muestra hoy en la actualidad, parece ser materia de un análisis abierto pero acotado donde se intentará entrever la debacle del objetivo prístino atisbado en su concepción.

1 Referencia a la pregunta: “¿Qué es aquello que no puede en ningún caso dejar de ser la Universidad, ni aún a pretexto de convertirse en el espejo de su tiempo? Para profundizar, véase Millas, Jorge. Idea y defensa de la universidad. Santiago, Chile: Editorial del Pacífico y CPU, 1981, p. 62 y ss. A propósito de la intemporalidad de la Universidad y del rasgo distintivo que le da su identidad. Así, -en términos aristotélicos- "la esencia" de un objeto o cosa es lo que le da su indivisibilidad y cualidad única, sin la cual dejaría de ser tal.

2 Con esa denominación, hago alusión a una parte de la herramienta metodológica de la "triple distinción" empleada por Orellana Benado que se refiere a las preguntas humanas, aquellas que tienen un rango que es abierto pero acotado de respuestas verdaderas, o correctas o dignas de ser estudiadas y conocidas, en suma, de ser tratadas con respeto. Este punto es desarrollado a grandes rasgos en Orellana, Miguel. Pluralismo. Una ética del siglo XXI, pp. 30-31 En su: Prójimos lejanos. Ensayos de filosofía en la tradición analítica. Santiago, Chile: Ediciones Universidad Diego Portales, 2011. 


\section{PROLEGOMENOS}

$\mathrm{Al}$ momento de analizar a la Universidad es necesario acudir al origen del término y de las razones que motivaron su surgimiento. En primer lugar, la Universidad es una institución ${ }^{3}$. ¿Por qué? - En la raigambre etimológica de la palabra, es posible hallar a universitas como el antecedente directo. Aquella expresión latina tenía asignado el significado de "asociaciones orientadas hacia una meta común". Ahora bien, ante la fundación de las primeras universidades en la Europa medieval se les agregarían las expresiones Magistrorum et scholarium, lo que en nuestro castellano es "maestros y alumnos". Entonces, la Universidad sería una asociación de estos últimos. Tenemos ya, el significado de la expresión en lo que por convenciones historiográficas se denomina "Edad Media". Una segunda consideración surge a partir de esas expresiones que ańadieron, que resulta un tema de "relaciones". La Universidad -en primer lugar- como institución y ahora, asociación de maestros y alumnos, orientada hacia una meta común. ¿Qué relación tienen los integrantes de esto? ¿Una relación de enseñanza-aprendizaje? -Para no entrar en un terreno en el que no soy docto, diré que resulta una dependencia de carácter cognitivo, no en el tema afectivo, sino que abocado al espectro del discutir, el ampliar el conocimiento, el que mi maestro me enseñe lo que yo no sé y lo que me causa curiosidad. Esencial a nivel de institución esto, puesto que la sociedad está estructurada a base de relaciones y estas, existen en tanto nos sentimos gratificados". Mencioné el hecho de "no saber" y de "curiosidad", lo que puede afirmar que el maestro contesta las interrogantes acerca del mundo, cosa que surge en el corazón de la humanidad, en los instintos, en ese enfrentamiento, confluencia, lucha y compromiso entre los instintos, nos diría Foucault ${ }^{5}$. En esto radicaría la persecución del conocimiento por parte de los alumnos, los que a través del vehículo que presentan los maestros podrían acceder de una forma más sencilla, sin perjuicio de lo escriturado e investigado (cuestión a analizar más adelante). El conocimiento proviene del método empleado por la filosofía que para nada constituye una teoría, sino más bien es una actividad ${ }^{6}$ que despliega el maestro. Esto nos deja con un pie circunscritos a la filosofía. No obstante, no puede limitarse a aquello, pues es solamente para explicar que la actividad del maestro constituye el método respecto del conocimiento, esto es sin perjuicio de la ciencia colaborativa e inductiva que pregonaría Francis Bacon en el paradigma de la modernidad. Para disuadir a los fantasmas que aparecen con el uso de la palabra filosofía en esta exposición, señalo que las enseñanzas del maestro vienen a ilustrar el camino hacia el conocimiento pleno, pues este se experimenta de manera personal e indivisible a nivel interno y luego se proyecta hacia el exterior ${ }^{7}$.

En los términos propuestos por Durkheim, vale decir, una forma de manifestación de las creencias y conductas de una comunidad. Véase Durkheim, Émile. Las reglas del método sociológico. D. F., México: Fondo de Cultura Económica, 1986, p. 31.

4 Krishnamurti, Jiddu. Sobre las relaciones. Madrid, Espańa: EDAF, 1994, pp. 25-30.

5 Foucault, Michel. La verdad y las formas jurídicas. Barcelona, España: Gedisa, 1996, pp. 21-33.

6 Wittgenstein, Ludwig. Tractatus Logico-Philosophicus. Madrid, España: Tecnos, 2003, p. 161.

7 A propósito de seguir instrucciones, una de las perimeras cosas que se aprenden en las instituciones educacionales. Metáfora al respecto (con un sentido satírico) en OrRego, Cristóbal. Las instrucciones del microondas. Santiago, Chile: Centro de Estudios Bicentenario, 2006, pp. 53-56. A modo de alegato a favor de la desmitificación del camino individual del conocimiento de- 
Señalado que la conjunción entre maestros y alumnos viene a ser la composición inicial de la Universidad, donde se agrupan en torno a un fin común: el compartir el conocimiento. ¿Para qué? - Motivados en la búsqueda de la verdad, una de las cosas que tanto interesa al hombre, sea cuál sea el campo del que la quiera obtener. La Universidad entonces, desde esa perspectiva quería mantener fuera a la ignorancia del mapa y asimismo, ilustrar al individuo. En clave baconiana, apartar a los ídolos, nociones que ocupan el entendimiento humano y hacen difícil el acceso a la verdad, ${ }^{8}$ tónica que se transformaría en el estandarte del "paradigma de la modernidad"'. Este último, que provocaría una revolución en la manera de ver a las instituciones, pues el cambio radical por el "temporal" desplome del tomismo post-1492 y un nuevo e imperante entendimiento del conocimiento (la ciencia experimental) serían culmines para malear la instrumentalización de la Universidad. Esta última sería instrumentalizada a partir de ese concepto entregado por los romanos y que luego, es modificado por los medievalistas hasta la entrada a la modernidad. Queda claro que el uso de la Universidad/su instrumentalización está dada por la obtención de conocimiento que vería violado su espacio conceptual, en otras palabras, su entendimiento actual. Esto sucede porque desde pasar de una concepción tomista del conocimiento, esto es, la utilización de Aristóteles para asuntos profanos/naturales y de los postulados del Aquinate para lo sagrado, llegaría a irrumpir el tema de la ciencia. Se segmentaría esa funcionalidad, el entendimiento tomista del conocimiento decrecería, quedando como una especie de posición favorable en el mundo intelectual de la Iglesia Católica y como una concepción más o menos anticuada ${ }^{10}$. Es importante esta ruptura epistemológica al interior de las universidades, por la creciente decadencia que enfrenta el mundo actual al respecto.

La ciencia/entendimiento moderno del conocimiento, bajo la fórmula "conocer para observar, para predecir hipótesis y en esos términos, medir y controlar el mundo", a partir de la óptica del empirismo británico se pondría en boga esta forma de tratar de llegar a la verdad de las cosas. El método científico sería una bandera de guerra frente a todas las otras "maneras de llegar a la verdad", junto a la secularización que hablaría de una relación más cercana del hombre con la naturaleza y también, lo que podríamos obtener con aquello que se denominara metáforas jurídicas de Bacon, o sea, "el torturar a la naturaleza para exigirle respuestas". ${ }^{11}$ Lo

sarrollada de forma minimalista bajo el nombre de escalera epistémica" en López, Nicolás. (Re)pensando realidades. <En línea> [citado 12 mayo 2012]. Disponible en World Wide Web: <http://www.fileden.com/files/2010/6/29/2901145/My\%20Documents/repensandorealidades.pdf> pp. 66-68.

8 BaCon, Francis. La gran restauración. Madrid, España: Alianza, 1985, p. 97.

9 Echeverría, Rafael. El búho de Minerva. Santiago, Chile: LOM Ediciones, 2004, pp. 10-14.

10 Esto es afirmado en primera instancia y luego, refutado en gran medida por uno de los reivindicadores del tomismo en la Inglaterra del siglo XX, Frederick Copleston. Para mayor referencia, véase Copleston, F. C. Aquinas. Londres, Reino Unido: Penguin Books, 1955, pp. 243-264.

11 La formulación del entendimiento moderno del conocimiento sería presentada por Orellana Benado en Orellana, Miguel. Tradiciones y concepciones en filosofía. En: NudLer, Óscar (ed.). Filosofía de la filosofía (Enciclopedia Iberoamericana de Filosofía, vol. 31). Madrid, España: Trotta, 2010, pp. 49-78. El argumento que expone al método científico como un paladín del entendimiento moderno de la ciencia, así como a la secularización como un rasgo distintivo de la modernidad, es posible hallarlo en ECHEverría, Rafael, op. cit. (n.9), pp. 19-23 y en una versión más coloquial, satírica, excéntrica y "poética”, véase Iвañez, José Miguel. Historia de la Filosofía. Santiago, Chile: Editorial Andrés Bello, 1983. Sin perjuicio de lo anterior, si se 
gracioso de todo esto, es que el método sería eficaz para adquirir conocimiento, pues el microscopio de la empiria tendría infalibilidad prácticamente en estos asuntos, sería algo así como una "ciencia verdadera", donde la experiencia viene a partir de los sentidos, la razón nos permite deducir leyes desde la experiencia, la demostración se constituye en el elemento clave junto a la verificación ${ }^{12}$. Al trabajo en conjunto de maestros y alumnos no se les pasaría un trabajo distinto de este para ir en busca del conocimiento y así también, la verdad. La lectura de los textos sagrados y filosóficos (Aristóteles, Platón y sus claves monoteístas: Maimonides, Averroes, Agustín de Hipona y el Aquinate) y la reflexión filosófica, así como en el campo de las "humanidades" en general quedaría relegada a un plano de "no-conocimiento", pues se pregonaría que lo que no es ciencia, no es conocimiento ${ }^{13}$. La observación atenta de la naturaleza que arroja interpretaciones pragmáticas, los signos que confirmar las creencias (a posteriori) y el rechazo a las cuestiones apriorísticas ${ }^{14}$ sería el trabajo "inductivo" entre maestros y alumnos. Ahora bien, eso junto a los cambios que se irían dando paulatinamente con el tiempo, detonarían la baja en la reflexión por parte de las universidades. Me refiero a procesos como: el aumento demográfico sostenido, el auge de las mejorías tecnológicas, el incremento en la expectativa de vida, la secularización de las instituciones, el imperio del entendimiento moderno del conocimiento (en términos de uso y búsqueda de la verdad) y la emergencia del capitalismo.

El último punto viene a cerrar el círculo expositivo al respecto del "para qué" es usada la Universidad o bien, instrumentalizada. Si bien, el paradigma de la modernidad tiene como estandarte a la ciencia, su proyección principal es el capitalismo, que propiamente tal, nace al alero del escocés Adam Smith en "The wealth of nations"15 de 1776. A partir de la premisa de la "acumulación de riquezas", porque eso es lo bueno per se, para un Estado. En esa misma línea, Smith plantea:

"la riqueza de un país no puede mantenerse estacionaria. Así no se lograrán mejores salarios. Si no hay movilidad y el capital se mantiene, no habrá necesidad de más trabajadores para cubrir cargos." 16

quiere ver un bagaje acerca de la adopción de las ciencias pre-modernidad en las distintas naciones y no asignar el valor en esa sola época a la ciencia, véase Al-Andalusí, Sầid. Libro de las categorias de las naciones. Madrid, Espańa: Ediciones Akal, 1999.

12 Da Vinci, Leonardo. True science. En: Richter, Irma (ed.). The Notebooks of Leonardo da Vinci. Oxford, Reino Unido: Oxford University Press, 1980, pp. 3-12.

13 Postulados que se prolongan hasta nuestros días, gracias al accionar del empirismo, el positivismo lógico, la concepción cientificista de la tradición analítica, el círculo de Viena y así también, el naturalismo que irradia a las ciencias físicas y matemáticas hacia las otras disciplinas que puede estudiar el ser humano.

14 También en Todorov, Tzvetan. La conquista de América. El problema del otro. D. F., México: Siglo XXI editores, 2007.

15 Sмiтh, Adam. La riqueza de las naciones. Buenos Aires, Argentina: Longseller, 2008.

16 Ibíd, pp. 42-43. Las cursivas son mías. 
El objetivo de los habitantes de un país es acrecentar la riqueza del mismo y esta, se consigue a través del "buen" empleo del capital y del trabajo, el que tiene que estar dividido, pues dice Smith que el hombre, durante su vida necesita continuamente ayuda y auxilio de los otros (toma el principio de colaboración de Bacon, al parecer). Entonces, la masa que compone un territorio y asimismo, un Estado tiene su preocupación en la labor de producción. Sin embargo, cabe la pregunta de si reflexiona en algún momento, ¿Existe un paseo a la skhole? Es posible indicar que en las Universidades se recorría muy poco el camino a ese templo, existiendo una disminución del estudio de las humanidades. La época se volcó hacia el comercio ${ }^{17}$, la producción y la ciencia, que generaba conocimiento empírico y por tanto, el válido, comprobable y susceptible de verificarse.

Entonces, la sociedad de ese período iba en busca del progreso, a partir del capitalismo. Sin embargo, en epistemología, intervendría el francés August Comte con su ley de los tres estadios de la ciencia ${ }^{18}$. Esta se describía como los pasos que tiene que seguir una disciplina para considerarse como ciencia, ergo, como conocimiento. Estos planteamientos serían más conocidos en la jerga académica como "positivismo", por el último estadio en el que la disciplina se convierte en ciencia, a través de la obtención de las cualidades de cuantificación y medición de los objetos cognoscibles por los sentidos, generando certezas y así, conocimiento apodíctico. Ahora, el progreso estaba dado también, por la tecnología y la ciencia como una manera de facilitar la vida de los seres humanos. Se sumaba a la acumulación de riquezas, que propugnaba que entre más "metales preciosos" tenía un país, más rico e importante era. Con el establecimiento de este sistema, quién tenía más recursos era quien se podía apropiar de más cosas e incluso, de todo lo que quisiera.

Sumado a lo anterior, el liberalismo -económico- que se convertiría en un modelo muy adoptado por ese tiempo, criticaría a la ciencia, señalando que si bien es conocimiento, para que sirva, debe ser eficiente y debe prestar utilidad. Los reformadores ingleses de la ética, también llamados utilitaristas introducirían el concepto de utilidad en el mapa teórico. Respecto de la eficiencia, ídem, pero de una forma implícita, desde un par de extrapolaciones del utilitarismo. Jeremy Bentham y John Stuart Mill, marcarían un hito en la forma "consecuencial" de las acciones y las reglas. Me referiré solamente al aporte del segundo, pues el primero se encasilla como un milleano primitivo, cuya teoría fue modificada y no tuvo la misma proyección que la de su predecesor.

17 Smith expresaba en su libro que "el progreso florece en aquellas zonas donde se facilita el comercio de toda especie de productos" (Sмiтн, Adam, op. cit. [n.16], p. 28). Esto evidencia que el progreso,-creo- de una sociedad era sinónimo de la actividad económica de los agentes que integran el mercado. Así también, la ciencia viene a fortalecer este proceso, pues yendo de la mano con la tecnología, podía propender a más progreso y por tanto, a la utilidad y eficiencia.

18 En Comte, August. Principios de filosofia positiva. Madrid, Espańa: La España Moderna, 1948, pp. 57-64 y Orellana, Miguel. Identidad, filosofía y tradiciones. En su: op. cit. (n.1), pp. 126-127. 
Unas palabras breves sobre el utilitarismo. Este se concibe -en una primera aproximación- como una teoría ética que intenta fijar un estándar de cómo llegar al fin máximo de la vida y también, señalar cuál es ese. Es teorizado por J. S. Mill, a partir del principio de utilidad, que es lo mismo que "la felicidad del mayor número". A esta se propende o bien, se sigue el principio en el marco de nuestras acciones, dependerá si son buenas (right) o malas (wrong). Las primeras propenden a la utilidad de los individuos. Es del marco pre-discursivo a esta cuestión el hecho de que el hombre actúa racionalmente cuando lo hace bien. Ahora bien, importa que exista tendencia hacia el bienestar colectivo. Respecto del individual, en un escenario macroscópico no parece importar, sí como condición para poder actuar bien ${ }^{19}$, seguido desde el aforismo "la caridad empieza por casa". Entonces en esa óptica, lo bueno es lo útil. Ahora bien, una pequeña distinción entre un utilitarismo de acto y uno de regla. Por un lado, el primero se refiere a que una acción lleva a la utilidad porque es buena. Por otro, el utilitarismo de regla, la evaluación es ex post por medio de una regla que le otorga la calidad de buena. Lo anterior supone $a$ fortiori que se legisle en términos de optimizar los resultados de nuestras acciones donde todo sea conforme al bien, a una noción que la mayoría tenga, pues de lo contrario quedarían individuos indiferentes con la consecución de la utilidad. ${ }^{20}$

¿Qué sería lo eficiente? - El conseguir la utilidad, la mayor felicidad de todos; la consumación de todo el modelo utilitarista a nivel estructural-social. Entonces, la misión de los individuos en la vida -acorde a este modelo- sería maximizar la utilidad, tender a ella, porque es lo bueno per se y lo eficiente. En economía -la disciplina imperante del siglo XX y probablemente de lo que va del XXI- esto se refiere a lo que retrataba Smith a propósito de la acumulación de riquezas. Asociatividad de modelos y obtenemos el vehículo para comprender el fenómeno de esa época ${ }^{21}$.

A eso, añada que el ser humano quiere poder y Hobbes nos diría que aquel, está dado por el dinero ${ }^{22}$. Este último, el medio para intercambiar bienes y servicios y así, maximizar la

19 Mill, John Stuart. Sobre la libertad. El sometimiento de las mujeres. Buenos Aires, Argentina: Aguilar, 2010, pp. 105-127.

20 A propósito del principio de utilidad: Mill, John Stuart. El utilitarismo. Madrid, Espańa: Alianza, 2007. Alrededor de la distinción entre utilitarismo de regla y de acto se encuentra un artículo de J. O. Urmson (cf. Urmson, James Opie. Interpretación de la filosofía moral de J. S. Mill. En: Foot, Philippa (ed.). Teorías sobre la ética. D.F., México: Fondo de Cultura Económica, 1994, pp. 188-199).

21 Al respecto, una contextualización con un poco más de detalle en López, Nicolás. Los utilitaristas contra las humanidades: Dos problemas contemporáneos. En: I Jornadas de Pensamiento Político (25, 26, 27 de abril de 2012, Concepción, Chile). Concepción, Chile: Universidad Católica de la Santísima Concepción, 5p.

22 Sмiтh, Adam, op. cit. (n.16), p. 31 y Новвеs, Thomas. Leviatán: O La materia, forma y poder de una república, eclesiástica y civil. D.F., México: Fondo de Cultura Económica, 2006, pp. 270-275. Luego se afirmaría que el objeto del deseo es el dinero -en una concepción post-hobbesiana, existencialista- lo que también sería una representación. En esos términos, un hombre joven rara vez podría llegar a envidiar a otros, sus capacidades, o su arte, o el amor de la bella mujer, o su fama; no, pero su dinero sí lo envidiaría. Palabras de Kierkegaard en KierkegaArd, Soren. La época presente. Santiago, Chile: Editorial Universitaria, 2001, p. 51. 
utilidad. Ciertas concepciones de la "libertad" expondrían que el dinero constituye un marco regulador de la misma. Por ejemplo, G. A. Cohen, hablaría que la falta de medios (dinero) es falta de libertad, porque me impide desarrollar determinadas actividades ${ }^{23}$.

He ahí el punto clave, el interés humano está en la utilidad, la eficiencia y el poder, conseguido este último, a través del dinero. Para objetivos de comprensión cabe tener presente que estos -según la argumentación anterior- tenderían al progreso de las sociedad y así también, la humanidad. ¿No olvidamos la ciencia? - No, viene incluida en las cosas útiles y eficientes que dan poder. Sólo ilustré ese cambio en el entendimiento del conocimiento, porque queda al descubierto que las reflexiones y las humanidades quedan relegadas (algo que originariamente se exponía como un medio de llegar a la verdad en el origen de este icono). Como institución, vemos que la Universidad se instrumentaliza de un modo distinto, pues -en el sentido durkhemiano- la manifestación de las creencias y conductas de una comunidad describe a las instituciones como tales.

Ahora bien, es -históricamente- reconocible que el ser humano en los últimos tres siglos se ha dedicado a: monetarizar su vida y girar en torno al eje económico. Lo mismo pasa paulatinamente en las Universidades. ¿Cómo? - Han sido penetradas por esa visión económica de la vida (como creencias y conductas), siendo la racionalidad "utilitarista" y en torno a lo eficiente la que se ha impuesto. Si se insiste preguntando cómo. La respuesta viene dada por lo que uno recibe al ir a la Universidad. El móvil es muy simple, pasaré a describirlo a continuación para entrar de lleno en la tercera sección.

Los alumnos participan en la institución con sus maestros con la finalidad de compartir experiencias, saber y así, enriquecer el plano espiritual ${ }^{24}$. Entonces, ¿Por qué va el alumno a la Universidad? - Para adquirir el saber y aumentar su capacidad reflexiva, con los medios que le ofrecen. Mucho hincapié en que no solamente están los maestros, sino que también, los textos que contienen el bagaje epistémico para confeccionar una doxa inquieta. Dicho eso, el alumno va a la Universidad para servirse de todos esos elementos y así, convertirse en un "ser pensante" (no en términos cartesianos). En esa línea, hay que tener presente que la Universidad otorgaba no solo herramientas, sino que certificaba la calidad de "ser pensante" en una determinada disciplina (lo que hoy es el título). Con eso último, el individuo estaba capacitado como experto para dar cuenta de problemas y exponer formas de resolverlos. ¿Había utilidad en eso? - Utilidad en los términos que se ha descrito, probablemente sí. El individuo instrumentalizaba a la

23 Cohen, G. A. "Libertad y dinero", en: Estudios Públicos, No 80, pp. 51-76. Santiago, Chile: Centro de Estudios Públicos, 2000 (primavera).

24 Aquí poco importa qué es lo que en cuestión se enseñaba, sino que lo relevante constituye que se transmitía un saber que problematizado podía entregar tanto respuestas como un método que pretende acercarse a la búsqueda de la verdad. Claramente el panorama se metamorfosea al calor de las vicisitudes sociales, es por eso, el tema del cambio del entendimiento del conocimiento y ese, que se ha posicionado como amo y señor de la reflexión. Esa sustitución evidencia el desdeñamiento contra el enriquecimiento espiritual, donde el pensar (operaciones apriorísticas) no sirven para generar conocimiento y por tanto, ya no son útiles ni eficientes. Así como tampoco no entregan poder (dinero). 
Universidad, pero el uso y el acceso no presuponían el que todos pudiesen convertirse en expertos. Smith lo señala a propósito de la división del trabajo. Lo mismo realiza Platón y Aristóteles cuando mencionan el ergon de un individuo, es decir su función específica en una determinada comunidad $^{25}$.

Sin embargo, al alero de los vientos que erosionaron esa concepción se aprecia la argumentación expuesta anteriormente, donde un cambio en la forma de ver el conocimiento se posiciona en estas instituciones. Adicionalmente, el cambio social respecto de la introducción de la utilidad, el progreso y el conseguir poder (dinero) influyó considerablemente. Ahora bien, los individuos se aliaban con los maestros con la intencionalidad de obtener la calidad de "ser pensante" y pensar en cómo podría ser útil para propósitos personales (la individualidad como elemento del bienestar ${ }^{26}$ ), dejando de lado la reflexión y dedicándose en exclusiva a la producción y acumulación de riquezas.

\section{CONSTRUCCIÓN DE UN RELATO CRÍTICO DE NUESTRA SOCIEDAD}

"Las sociedades siempre avanzan. Asi debe ser. (...) Los jóvenes no solo deben transitar por el presente y hacerse cargo de lo que escuchan, también deben conocer, reflexionar, comparar... "27

Una descripción deontológica y un poco idealista, del otrora Premio Nacional de Historia, Eduardo Cavieres.

De eso para con la Universidad intentaré retratar en este apartado.

Acorde a la frase de Cavieres, ciertamente las sociedades avanzan. Sin embargo, hay un paso firme que se hace al alero de la ciencia (y así también, del cientificismo) y de la economía. Hoy, parece ser que todo es susceptible de análisis económico, porque así las decisiones pueden revestir un carácter de racionalidad. Entonces, los comportamientos de los individuos están impregnados de esta "irreflexión", que en el fondo no es tan racional, pues lo sujeta a la producción y al mercado. Marx en "El Capital" expone que el capitalismo está sujeto a ciclos que se repiten cada cierto tiempo y cuya particularidad en el final que pasa a constituir un feedback, es cuando se llega al estado de abundancia, donde la producción es destruida por los capitalistas para tener una pérdida "menor" y más racional. ${ }^{28}$ Esto ejemplifica en cierta manera que bajo

25 Descripción de este concepto y de cómo ser ordenaba una sociedad en proporción de funciones en VIGO, Alejandro. Aristóteles. Una Introducción. Santiago, Chile: IES, 2007, pp. 190-207.

26 Véase n.21.

27 CAVIeres, Eduardo. Bicentenario en retrospectiva, logros y deudas históricas: La construcción del discurso y los contenidos de las realidades. En: Medina, Andrés, et al (eds.). Los Bicentenarios de las Independencias y los procesos de integración. Concepción, Chile: Editorial Universidad Católica Santísima Concepción, 2011, p. 57.

28 Cf. MarX, Karl. El Capital: Libro segundo: El proceso de circulación del capital. Buenos Aires, Argentina: Siglo XXI editores, 2004, pp. 117-142. 
el velo de la racionalidad, el individuo va en busca de maximizar sus utilidades y también, sus riquezas. Él es poderoso en términos monetarios. Ahora bien, como gasta la mayor parte de su tiempo, trabajando y produciendo, ¿Cuándo tiene tiempo para pensar, para el ocio o bien, para realizar una labor investigativa en temas no científicos (apriorísticos)? Al parecer, no lo tiene. Ciertamente no todos los individuos obedecen a ese patrón, pero la mayoría sí. Esos mismos que obedecen a la conducta de comportarse competitivamente, donde todos quieren lo mismo: poder (dinero) y utilidades. ${ }^{29}$ En esta misma línea, ¿Quiénes son los que tienen las riquezas? Las elites terratenientes, la aristocracia u oligarquía (sin perjuicio de los consensos historiográficos en Chile). Parece ser que no se dedican al ocio y sólo a producir lo que puede darles poder (dinero). No es lógico argumentar esto a secas, como si fuese malo lo que hacen. Es solo que para constituirse de forma integral o bien, para que no naufrague un proceso -cognitivo- que es intrínseco al ser humano, es necesario que se realice.

La Universidad debería posibilitar eso en su instrumentalización, si bien, para eso surgió. Ahora bien, la sociedad es la que baña de prejuicios, pre-conceptos y entendimientos (impuestos) categóricamente tajantes y un tanto, taxativos. Señalé que es esa misma sociedad la que tiene esparcida esa monetarización de la vida y el problema del arribismo epistemológico ${ }^{30}$. Pero la sociedad per se no hace eso, si lo vemos desde una óptica elevada, sino que son los grupos privilegiados, la que describí anteriormente -y que también Nietzsche sindica- como "aristocracia". $\mathrm{Al}$ respecto, el alemán esboza lo siguiente:

"La especie aristocrática de hombre se siente a si misma como determinante de los valores, no tiene necesidad de dejarse autorizar, su juicio es: 'lo que me es perjudicial a mí, es perjudicial en sî́; sabe que ella es la que otorga dignidad en absoluto a las cosas, ella es creadora de valores. Todo lo que conoce que hay en ella misma, lo honra; semejante moral es autoglorificación."31

En la cita de Nietzsche, se identifica un punto clave, la hiper-imposición de la aristocracia, en virtud del poder que posee. A propósito de "la riqueza de las naciones", donde el Estado que más tuviera, más poder tendría en su mano. Lo mismo ocurre a nivel individual, pues el dinero es amo y señor de las circunstancias, las sociedades y todo lo que implica, todo a causa del

29 Habrá autores que señalarán que la competencia es intrínseca al ser humano, como Von HAYEK, Friedrich. "La competencia como proceso de descubrimiento", en: Estudios Públicos, No 50, pp. 1-11. Santiago, Chile: Centro de Estudios Públicos, 1999. Sin embargo, no parece ser así, pues el modelo capitalista y el mercado incoan a la condición del homo homini lupus en la raza humana (Hobbes). Si existiese comunidad perfecta o bien, si la búsqueda del conocimiento sin incentivo monetario o remuneración, fuese el placer del individuo el panorama sería distinto. Ídem a si fuese la tarea central. Si bien, hay individuos que se tienen que mantener en el plano físico y técnico, yo me refiero a los que entran a la Universidad y la instrumentalizan de forma que la reflexión, el opinar y el buscar la verdad sean las piedras de tope en su norte.

30 Dice relación con colocar a la ciencia como estandarte de las actividades y de la obtención del conocimiento. Sin embargo, mayor referencia en Orellana, Miguel. "Arribismo epistemológico, ciencia y tecnología”. En su: op. cit. (n.1), pp. 144-158.

31 Nietzsche, Friedrich. Más allá del bien y del mal. Buenos Aires, Argentina: Gradifco, 2007, p. 161. 
paradigma de la utilidad y eficiencia. Esa imposición -brusca- es una de las causas de la falta de reflexión. Encontramos que es esa elite la que es causa de estos males. Sin embargo, recalco que la causa de las causas viene a ser el panorama monetarizador, pero ya dilucidaré la bruma acerca de esto.

A propósito del arribismo epistemológico, este sostiene que la acumulación de conocimiento científico hace posible la tecnología, la cual constituye la clave del desarrollo de un Estado. Ahora bien, Orellana Benado identifica al respecto que:

"Solo con humanidades para el desarrollo podremos (...) evitar los riesgos de un enfoque que reduce a la ciencia y la tecnología a sus descubrimientos y aplicaciones tecnológicas, por importantes que pudieran ser sus contribuciones..."32

Eso debería posibilitar la Universidad, junto a libros, buenas condiciones de espacio, oportunidades de intercambio y perfeccionamiento académico constantes, con el fin de atraer a esas actividades el talento que nunca falta ${ }^{33}$. Pero no, se enfrasca en la lucha por maximizar utilidades, a partir de la obtención de una certificación que sindica al individuo como "ser pensante". Ahora ya, está la utilidad. La institución -ya no en términos durkhemianos, sino que como una característica de la arqueología de un momento histórico- debería conservar el motivo por el cual fue creada y no debe prostituirse para mal. La Universidad debe tener ese objetivo, de la búsqueda del conocimiento, no de maximizar utilidades a partir de herramientas que otorga para "lucrar". Para eso, debería existir una institución -en términos de establecimiento- que realizase dicha función.

\section{UNIVERSIDAD Y ARISTOCRACIA}

Prácticamente el final respecto del arribismo epistemológico fue una cortapisa del argumento de la aristocracia, el que desarrollaré en extenso en este apartado.

Hay un tema pendiente en la frase de Cavieres expuesta al inicio de la sección pasada y dice referencia con que los jóvenes no solo deben transitar por el presente y hacerse cargo de lo que escuchan, también deben conocer, reflexionar, comparar. Una prevención: si bien, está dirigido a los jóvenes, es por un tema del camino que han recorrido, que es poco. Creo también que a los viejos, a los infantes e incluso a los neonatos (si es que no exagero) debe ser extensiva esa frase, para que no guarde un tinte huidobrista de "querer echar a los viejos para que lleguen los jóvenes"34.

32 Orellana, Miguel, op. cit. (n.31), p. 154.

33 Ibíd.

34 Cf. Huidobro, Vicente. Balance patriótico. <En línea> [citado 10 mayo 2012]. Disponible en World Wide Web: <http:// www.saladehistoria.com/Historia_Chile/Fuentes/Huidobro_1925.pdf> 
La aristocracia en virtud de su poder económico, concentra las riendas de las sociedades (un panorama capitalista y bastante injusto), esto mismo hace referencia a una restricción y una delimitación de la libertad. ¿Por qué no hay reflexión? - Es un cierre esta pregunta, pero la respuesta viene a ser: hay reflexión, pero poca. Sin embargo, es como si no hubiera (al menos en las Universidades). Lo que se da al interior de las Universidades es una reproducción de lo que imponen las elites, que por lo demás, son ignorantes -en términos de una preocupación sostenida y sistemática respecto de su quehacer- y no tienen tiempos de ocio.

La economía habla de necesidades que hay que satisfacer, es por esa razón que vamos a producir para maximizar las utilidades y ese es el panorama de una sociedad. No obstante, argumenta Marcuse que es una forma de control, con lo que se coopta a la autonomía personal, a continuación cito un pasaje de "El hombre unidimensional":

"Una sociedad que parece cada día más capaz de satisfacer los intereses de los individuos por medio de la forma en que está organizada, priva a la independencia de pensamiento, a la autonomía y al derecho de oposición política en su función crítica básica." 35

Queda claro que la imposición aristocrática demuele la autonomía para realizarse, así como también para pensar/reflexionar. No hay referencias acá a la censura (ni ex ante ni ex post), sino más bien, a una incapacidad -inconsciente- de reflexionar por parte de las personas, pues están enceguecidas por la "maximización de utilidades".

"La verdad, en efecto, posee cierta natural virtud de agradar; pero este es un privilegio que (...) se ha concedido a los necios." 36 Erasmo de Rótterdam nos entrega ese pasaje en su "elogio de la locura". Aquél hace referencia a esa que es pregonada como verdad, ese entendimiento que se impone y que no es susceptible de críticas, y que también, es un privilegio de los aristócratas. Asimismo, llamados "necios", por un tema que ya describí. Las sociedades están siendo cada vez más estultas (en eso pensaría Erasmo, también) -en el sentido de que no hay reflexión al interior- sino que preocupación por querer parecerse a las elites. ¿Y cómo puede ocurrir eso? - Primera respuesta: mimesis ${ }^{37}$. No obstante, hay que distinguir tres fases en esto, a saber: a) Pensando y comportándose igual; b) Produciendo igual, en cierta medida; c) Inmiscuyéndose en los círculos aristocráticos. Viene a ser un diagnóstico más delicado el revisar cada uno de manera detenida, por lo mismo, serán vistos desde la relación con la Universidad.

35 Marcuse, Herbert. El hombre unidimensional. Barcelona, España: Ariel, 1981, pp. 31-32. Las cursivas son mías.

36 De Rotterdam, Erasmo. Elogio de la locura. Barcelona, España: Ediciones Folio, 2007, p. 67

37 A contrario sensu de la adaptación, surge la mimesis, de modo que el sujeto se identifica con una determinada forma de hacer las cosas que es aparente -y simuladamente- la verdadera manera y es incuestionable, en los términos no-prohibitivos, sino que por la incapacidad de desarrollar un pensamiento opuesto. A propósito de este argumento, también en MARcuse, Herbert, op. cit. (n.36), p. 40. 
a) Pensando y comportándose igual. Esto viene a ser el primer paso -representativo- en la mimesis. ¿Cómo puede hacerlo? - Primera aproximación, adoptando la opinión del aristócrata en temas tanto contingentes como en los baladíes acerca de la vida. Respecto del comportamiento, la manera de expresarse y de observar los móviles antes de actuar tienen una pauta rígida trasuntada de ese individuo. ¿Cómo puede pensar igual? - Mirando las mismas transmisiones, leyendo las mismas obras (incluyo todo lo literario), yendo a las Universidades de su sello (si no hizo esto y cayó en alguna otra, se subsana acercándose a los sectores impregnados de "elite") y reproduciendo un discurso homogéneo que guarde caracteres de total similitud con el de ellos. Es simple, el individuo pierde su capacidad autónoma de autodeterminar su pensamiento; un tremendo vicio. Deja de lado la emergencia de los pensamientos, la necesidad de valerse por sí mismo en términos intelectivos. Se somete a esa voluntad, a ese designio preestablecido. Nietzsche pensaría que es una violación a esto de la naturaleza humana, porque va contra la cualidad intrínseca de ser una "maquina pensante". ${ }^{38}$ El hecho de pensar igual sin la capacidad de desarrollar matices o bien, críticas constituye -aunque el individuo esté consciente y tenga claridades respecto de una determinada cosa- ignorancia, no en términos categóricos, pero sí a grandes rasgos, porque hay un sometimiento intelectual y una pérdida/falta de libertad. Ya deja de ser ilustrada la sociedad ${ }^{39}$. Ahora bien, parte de la literatura "culta" ha sindicado que la Universidad debería ilustrar al individuo, de tal forma que exista especialización y pueda existir un mecanismo de feedback para los que quieran reflexionar acerca de asuntos complejos. Por ejemplo, la Universidad de Chile tenía como objetivo -en su fundación como tal- "crear una institucionalización que hiciera posible la creación de conocimiento" ${ }^{40}$. Kant exponía que el uso público de la razón debe ser siempre libre, puesto que esto lleva a la Ilustración entre los hombres ${ }^{41}$, por tanto este diálogo a viva voz para todos, supone la existencia de reflexiones interpersonales y que también da cabida a la crítica. Es importante que las Universidades cumplan ese rol como institución -entiéndase en torno a la funcionalidad-y que sea sólo ese. El formativo -en términos

38 De esta paráfrasis de Nietzsche, lo que no expone con claridad -y precisión conceptual- es "naturaleza humana". Sin embargo, lo señala como una condición o bien, un pre-requisito de ser "humano, demasiado humano". Son los hombres los que piensan, los que comen significado -en términos aristotélicos-. El punto central sí, es que el hecho que se imponga un entendimiento estático sin la posibilidad de reflexionar es lo que va contra esa condición. Una idea similar es expresada en Nietzsche, Friedrich. La genealogía de la moral. Buenos Aires, Argentina: Gradifco, 2004, pp. 15-25.

39 A modo de entender el concepto de ilustración para los propósitos de este trabajo, pienso en el postulado de KANT, Immanuel. “Respuesta a la pregunta: ¿Qué es Ilustración?”. En: Erhard, J. B, et al. ¿Qué es Ilustración? Madrid, Espańa: Tecnos, 1988, pp. 9-21. Este hace referencia a que es ilustración, la salida del hombre de su autoculpable minoría de edad. Esta última significa la incapacidad de servirse de su propio entendimiento sin la guía de otro. Uno mismo es culpable de esta minoría de edad cuando la causa de ella no reside en la carencia de entendimiento, sino en la falta de decisión y valor para servirse por sí mismo de él sin la guía de otro.

40 Serrano, Sol. Universidad y nación. Chile en el siglo XIX. Santiago, Chile: Editorial Universitaria, 1994, p. 103.

41 Kant, Immanuel, op. cit. (n.40), pp. 11-12 
peyorativos- para la mano de obra o bien, para gestar a las llamadas "profesiones liberales" que servirían a la comunidad al momento de aplicar el saber de una manera no tan acabada como la que describo, debería estar a cargo de otra institución y si se plantea que el individuo no tiene libertad de elegir por esa distinción tajante, se responde que el cambio es libre. ¿Por qué es esto? - Porque de no ser así, se desvirtuaría la instrumentalización de la Universidad y no es de carácter homogéneo como se planteó al realizar la genealogía del concepto. Lo que expongo dice relación a ese cambio de objetivo, de fin. La Universidad debe ser considerada como un espacio de expansión del conocimiento, de investigación, de crítica, porque la búsqueda de la verdad es algo muy cruel que no solo toma un par de vigilias, sino que puede imputársele que es "una forma de vida". De esa forma, se respetaría una especie de pluralismo "institucional", donde las Universidades podrían dentro de su objetivo tener a su haber lo que señalé anteriormente. La crítica es fundamental para entender todo este algoritmo, cuando existe un pensamiento que abandona su elemento crítico se convierte en una herramienta muerta que contribuye -sin querer- a transformar lo positivo que había hecho en algo negativo y destructor ${ }^{42}$. Eso es lo que le pasó al entendimiento que los individuos están tratando de trasuntar. Si la Universidad no nos libra de ese pecado, ¿Quién lo hará?

b) Produciendo igual, en cierta medida. Dice relación con el cuidado y la preocupación por el trabajo, el acrecentar el patrimonio, la acumulación de riquezas y la maximización de utilidades. ¿Para qué? - Porque ellos tienen poder económico, si yo quiero ser como ellos, tengo que tener esa facultad de adquirir sin problemas, pues podría dominar como ellos. Prejuicios y pre-ocupaciones ${ }^{43}$ impregnan esta visión de la realidad. Ahora bien, ¿Cómo llego a producir tanto? - El presupuesto de existencia de este paso en la mimesis es que la elite tiene muchísimos recursos. Se llega a través de una ocupación bien remunerada hasta el punto de poder maximizar tanto las utilidades no para llegar a ser como ellos, sino que para tener un estándar considerable, pero aún inferior al que poseen ellos. Igualarlo, imposible. Es necesario que pasen generaciones para que se asemeje al de los aristócratas en el momento que lo quería el individuo. Cosa de las injusticias sociales. ¿Cómo maximizaría las utilidades, entonces? - Adquiriendo una ocupación bien remunerada expuse, pero ¿cuál es esa? - Generalmente es una profesión liberal, adquirida cuando la Universidad me entrega un título de "ser pensante". Entonces, yo instrumen-

\footnotetext{
Horkheimer, Max y Adorno, Theodor. Dialéctica de la Ilustración. Madrid, España: Trotta, 1998, p. 52.

43 Bacon los asemejaría a los ídolos que el propone, véase n.9. En materia de prejuicios también se podría extrapolar a la división que realiza Gadamer a propósito de prejuicios de autoridad y los prejuicios de precipitación. Siendo el primero -en el que más se incurre y que quiere apartar la Ilustración- que se refiere a la sumisión a la autoridad. No así el segundo, que dice relación como una fuente de errores en el uso de la razón. El argumento completo en GadAmer, Hans-Georg. Verdad y método I. Salamanca, España: Ediciones Sígueme, 1999, pp. 338-348.
} 
talizo -y capitalizo- a la Universidad como un centro de movilidad social y nada más que eso, la llamada "mentalidad profesional" ${ }^{4}$. Ignoro el tema de la reflexión e Ilustración que he venido señalando y le asigno un valor ajeno al prístino.

c) Inmiscuyéndose en los círculos aristocráticos. Este punto es el paso más sencillo. ¿Por qué? - Porque una vez que el individuo ha pasado las dos etapas anteriores, está listo para codearse con la elite. Ahora bien, tema distinto es si es aceptado o no, pero tendería a decir que por el proceso de mimesis, en principio no habría problema. Eso sí, solamente si el algoritmo es exacto, o sea, perfecto. Si el individuo piensa y se comporta como la elite y si ha producido lo suficiente para que estos "colosos" lo admitan en su selectivo círculo.

La Universidad ha sido y sigue siendo utilizada como un medio y no como un fin. Vista como un instrumento del capitalismo y no del conocimiento, algo que haría llorar a quienes crearon la institución como una asociación de alumnos y maestros reunidos alrededor de un tema en común: la producción de conocimiento y la búsqueda de la verdad. De eso da cuenta esta especie de distinción tripartita. La sociedad fue adobada con cloroformo y cae en un sueño pseudodogmático.

\section{CONCLUSIONES}

"Las universidades se han transformado 'en pequeñas uniones soviéticas'. Y eso se nota pues con el mismo 'capital humano' se han ido construyendo 'think tanks' que traen la 'politica pública' de moda y la ponen en un paper." 45

$\mathrm{Al}$ respecto de las Universidades hoy en día, así parece ser, pues la elite juega para la elite y así se produce una especie de rutinización de esta dominación que ejercen sobre las instituciones. Extraigo de esta opinión, el hecho de que la historia arrojó en una primera aproximación el concepto prístino de lo que es la Universidad, luego de forma pletórica llegaría la arremetida de la ciencia al ver que el tomismo cometió un error estructural-funcional en la interpretación del mundo y como forma de obtener conocimiento. Los liberales tendrían participación también, con el planteamiento del principio de utilidad, la maximización de utilidades, la eficiencia y la acumulación de riquezas. Todas esas causas, gestarían el surgimiento de una aristocracia adinerada y poderosa, pero ignorante ${ }^{46}$ que se impondría en una sociedad metamorfoseada por esta manera de ver al mundo.

Véase Orrego, Cristóbal, op. cit. (n.8), p. 70.

45 Garin, Renato. Después de la República. Para un republicanismo del siglo XXI. Santiago, Chile: Instituto Democracia y Mercado, 2010, p. 23. La cursiva es mía.

46 Prevención: la aristocracia descrita a lo largo del texto tiene una raigambre de carácter burguesa, a propósito de las migraciones, el nacimiento de los Estados y el fin del feudalismo. 
Lo anterior derivaría en que la Universidad dejaría de ser pensada como un instrumento que vio su nacimiento a partir de la conjunción de maestros y alumnos en busca de la verdad. La prostitución de la Universidad dirán otros, donde otro objetivo que se suma a la lista se constituyó en un centro de formación de trabajadores con la "mentalidad profesional". Sol Serrano expone que en el caso paradigmático de la Universidad de Chile, se falló con la consecución de lo primero, señalando que la prostitución era inminente ${ }^{47}$.

¿Y la reflexión? - En el tacho de la basura. Enriquecimiento material que causa un empobrecimiento espiritual. La gente dejaba de tener una doxa propia y se limitaba a reproducir frases/consignas pre-existentes que tampoco admitían crítica. La sociedad iba en decadencia, como si padeciese un cáncer (casi) terminal. No existía libertad intelectual ${ }^{48}$, uno de los principios de occidente. Asimismo, el hombre no tenía el derecho a decir/imprimir lo que él cree que es la verdad. Estaba imposibilitado de discutir y llegar al punto de la crítica, sólo debía asimilar lo que venía. Una sociedad sin la capacidad de revisar las premisas que la imperan es afirmar la existencia de una naturaleza humana horizontal -y negativa- que denota una igualdad (bien relativista). J. S. Mill señalaba que "para dejar campo libre a la naturaleza de cada uno es esencial que personas diferentes tengan la posibilidad de llevar diferentes vidas" ${ }^{39}$. Por tanto, el encuentro en la Universidad de posturas distintas y el que exista un lugar en que se pueda buscar el conocimiento, constituye -quizás- el fin de este.

Mencioné que la Universidad debía ser vista como un fin en sí mismo. Porque mediatizarla solo trae como consecuencia su monetarización. Si ocurre este fenómeno, la Universidad solo será vista desde la óptica del análisis económico y se apreciará cuán bien maximiza las utilidades y es eficiente en el proceso de asignación de recursos. Esto del óptimo de Pareto que se encuentra cuando es rentable y capital una determinada empresa, en este caso, la Universidad sería algo así. No es la idea que un "templo del conocimiento" se prostituya al mejor postor. La idea no es "nivelar hacia abajo" 50 , porque la producción y valoración de conocimiento cae al purgatorio y por tanto, se concentra en el conjunto de la nada. Si ese proceso se diese por consumado totalmente, la Universidad estaría en peligro de extinción.

Si bien es cierto que este artículo no va dirigido para la totalidad de la población, sino más bien enfocado a denunciar ciertas costumbres y patrones se observan en la sociedad del hoy. Esperemos que a la gente que cultiva el conocimiento -humanista- no le tengan que dar

\footnotetext{
Serrano, Sol, op. cit. (n.41), pp. 149-167.

48 Véase Orwell, George. "Prólogo: La libertad de prensa." En su: Rebelión en la granja. D.F., México: Editorial Porrúa, 2007. En la parte que expone acerca del debate público, acuña esa expresión.

49 Mill, John Stuart, op. cit. (n.21), p. 115

50 El argumento desarrollado en forma extensa en Atria, Fernando. Mercado y ciudadanía en la educación. Santiago, Chile: Editorial Flandes indiano, 2007, pp. 85-88
} 
el consejo que Bello le dio a Barros Arana ${ }^{51}$. La Universidad debe ser "cuna y cajón" de la confluencia de múltiples entendimientos sobre las cosas, puesto que "es la diversidad de interpretaciones (...) la que nos hace sostener que todas las interpretaciones son igualmente respetables y sólidas, ni la arrogancia de creer que solo la propia lo es" 52 . En el caso paradigmático aún, citaré un discurso de Bello a continuación: “JJóvenes chilenos! aprender a juzgar por vosotros mismos, aspirad a la independencia de pensamiento" ${ }^{53}$ No es deseable que la Universidad saque solo profesionales o bien, gente docta en una disciplina que se proyecta a las artes prácticas, a la techné (expondría Aristóteles). Eso sólo produciría para la sociedad -y el mundo académico, sólo si lo alcanza, por las vicisitudes de la disciplina-, puercoespines. La instrumentalización de la Universidad, siguiendo ese fin primigenio, llamaría a entregar zorros al mundo intelectual. Los puercoespines pueden emanar de otras instituciones que no son la Universidad propiamente tal, como ya lo señalé antes ${ }^{54}$.

\section{REFERENCIAS BIBLIOGRÁFICAS}

Al-Andalusí, Sâiid. Libro de las categorías de las naciones. Madrid, España: Ediciones Akal, 1999.

Atria, Fernando. Mercado y ciudadanía en la educación. Santiago, Chile: Editorial Flandes indiano, 2007.

BACon, Francis. La gran restauración. Madrid, España: Alianza, 1985.

51 Cuando Barros Arana era aún periodista del Mercurio de Valparaíso, tuvo la suerte de entrevistar al rector de la Universidad de Chile, quien le dio el siguiente consejo: "Escriba joven sin miedo, que en Chile nadie lee". Frase que tiene mucho sentido, pero en Chile se lee poco y mal. Entonces, las reflexiones deben manifestarse en el ámbito público.

52 Orellana, Miguel. Allende: Alma en pena. Santiago, Chile: Demens \& Sapiens, 1998, p. 33. Atentos al concepto interpretación, pues debe entenderse en sentido lato, llegando la soga a contemplar términos como opinión, pensamiento y otros relacionados.

53 Bello, Andrés. "Modo de estudiar la historia", en: El Araucano <En línea> Santiago, Chile, 1848. [Citado el 12 Enero 2012] Disponible en la World Wide Web: <http://www.ensayistas.org/antologia/XIXA/bello/index.htm> Las cursivas son mías.

54 Esta idea de los zorros y puercoespines viene de la fabula/analogía contenida en BERLin, Isaiah. The hedgehog and the fox: An essay on Tolstoy's view of history. Londres, Reino Unido: Wiedenfeld and Nicolson, 1953 y en Orellana, Miguel. "El cosmopolita en la azotea: Isaiah Berlin y 'el siglo terrible”. En su: op. cit. (n.1), pp. 231-247. La mencionada "sátira" reza sobre una frase de Arquíloco que dice: "muchas cosas sabe el zorro, el puercoespín solo sabe una cosa grande". Esto queda incompleto sin el aporte de Berlin que elucubra para clasificar a los creadores de ideas. Sin embargo, yo la aplico con al contexto de cómo se ven ciertas personas que instrumentalizan a la Universidad en el sentido primigenio ya descrito hasta el cansancio en estas líneas y los que van por un "título". Los que solo saben hacer una cosa (como el puercoespín, que siempre se eriza) y buscan imponerla en todos los campos, lo que pasa con "los profesionales en un área" y aquí, abogo por la expresión de Orrego Sánchez, "la mentalidad profesional", véase nota n.45. Asimismo, lo puedo describir en una frase más coloquial que hace referencia a "los que solo saben hacer plata, viven, se angustian y mueren por eso". Y los que saben hacer muchas cosas (como el zorro) y que buscan caminos apropiados a cada situación. Estos últimos son los que tienen el plus de la reflexión que entrega una asociación de maestros y alumnos que se conjuntan para ir en la "sagrada" búsqueda de la verdad. Recuerdo la siguiente cita, al respecto: "el gozo de la lectura, del saber y del pensar, viene a menudo de la mano de la dificultad y del sufrimiento propios de la esforzada persecución de la verdad, tan amada y tan esquiva como todos los amores altos", las cursivas son mías, el texto original en ORREGO, Cristóbal. "Estudio preliminar". En: Finnis, John. Ley natural y derechos naturales. Buenos Aires, Argentina: AbeledoPerrot, 2000, p. 9. Comparto esa idea, la búsqueda de la verdad, uno de los estandartes de la vida humana. Ojo que solo está circunscrito al tema del pensar -en este caso- como bien lo marcan mis cursivas. Respecto del saber y la lectura, podrían haber mucho más ensayos de acá en adelante. 
Bello, Andrés. "Modo de estudiar la historia", en: El Araucano <En línea> Santiago, Chile, 1848. [Citado el 12 Noviembre 2011] Disponible en la World Wide Web: http://www.ensayistas.org/antologia/XIXA/bello/index. htm

Berlin, Isaiah. The hedgehog and the fox: An essay on Tolstoy's view of history. Londres, Reino Unido: Wiedenfeld and Nicolson, 1953.

CAvieres, Eduardo. Bicentenario en retrospectiva, logros y deudas históricas: La construcción del discurso y los contenidos de las realidades. En: Medina, Andrés, et al (eds.). Los Bicentenarios de las Independencias y los procesos de integración. Concepción, Chile: Editorial Universidad Católica Santísima Concepción, 2011.

Cohen, G. A. "Libertad y dinero", en: Estudios Públicos, No 80, pp. 51-76. Santiago, Chile: Centro de Estudios Públicos, 2000 (primavera).

Comte, August. Principios de filosofía positiva. Madrid, España: La España Moderna, 1948.

Copleston, F. C. Aquinas. Londres, Reino Unido: Penguin Books, 1955.

DA Vinci, Leonardo. "True science". En: Richter, Irma (ed.). The Notebooks of Leonardo da Vinci. Oxford, Reino Unido: Oxford University Press, 1980.

De Rótterdam, Erasmo. Elogio de la locura. Barcelona, España: Ediciones Folio, 2007.

Durkheim, Émile. Las reglas del método sociológico. D. F., México: Fondo de Cultura Económica, 1986.

Echeverría, Rafael. El búho de Minerva. Santiago, Chile: LOM Ediciones, 2004,

Foucault, Michel. La verdad y las formas jurídicas. Barcelona, España: Gedisa, 1996.

GadAmer, Hans-Georg. Verdad y método I. Salamanca, España: Ediciones Sígueme, 1999.

Garín, Renato. Después de la República. Para un republicanismo del siglo XXI. Santiago, Chile: Instituto Democracia y Mercado, 2010.

HobBes, Thomas. Leviatán: O La materia, forma y poder de una república, eclesiástica y civil. D.F., México: Fondo de Cultura Económica, 2006.

Horkheimer, Max y Adorno, Theodor. Dialéctica de la Ilustración. Madrid, España: Trotta, 1998.

Huidobro, Vicente. Balance patriótico. <En línea> [citado 10 mayo 2012]. Disponible en World Wide Web: <http://www.saladehistoria.com/Historia_Chile/Fuentes/Huidobro_1925.pdf>

Ibañez, José Miguel. Historia de la Filosofía. Santiago, Chile: Editorial Andrés Bello, 1983.

JaEger, Werner. Paideia: Los ideales de la cultura griega. Libro tercero: En busca del centro divino. D.F., México: Fondo de Cultura Económica, 2001.

Kant, Immanuel. “Respuesta a la pregunta: ¿Qué es Ilustración?”. En: Erhard, J. B, et al. ¿Qué es Ilustración? Madrid, España: Tecnos, 1988, pp. 9-21.

Kierkegaard, Soren. La época presente. Santiago, Chile: Editorial Universitaria, 2001.

Krishnamurti, Jiddu. Sobre las relaciones. Madrid, España: EDAF, 1994.

López, Nicolás. (Re)pensando realidades. <En línea> [citado 12 mayo 2012]. Disponible en World Wide Web: < http://www.fileden.com/files/2010/6/29/2901145/My\%20Documents/repensandorealidades.pdf >

Los utilitaristas contra las humanidades: Dos problemas contemporáneos. En: I Jornadas de Pensamiento Político (25, 26, 27 de abril de 2012, Concepción, Chile). Concepción, Chile: Universidad Católica de la Santísima Concepción, 5 p.

Marcuse, Herbert. El hombre unidimensional. Barcelona, España: Ariel, 1981. 
Marx, Karl. El Capital: Libro segundo: El proceso de circulación del capital. Buenos Aires, Argentina: Siglo XXI editores, 2004.

MrLL, John Stuart. Sobre la libertad. El sometimiento de las mujeres. Buenos Aires, Argentina: Aguilar, 2010. El utilitarismo. Madrid, España: Alianza, 2007.

Millas, Jorge. Idea y defensa de la universidad. Santiago, Chile: Editorial del Pacífico y CPU, 1981.

Nietzsche, Friedrich. Más allá del bien y del mal. Buenos Aires, Argentina: Gradifco, 2007. La genealogía de la moral. Buenos Aires, Argentina: Gradifco, 2004.

Orellana, Miguel. Prójimos lejanos. Ensayos de filosofía en la tradición analitica. Santiago, Chile: Ediciones Universidad Diego Portales, 2011.

"Tradiciones y concepciones en filosofía”. En: Nudler, Óscar (ed.). Filosofía de la filosofía (Enciclopedia Iberoamericana de Filosofía, vol. 31). Madrid, Espańa: Trotta, 2010, pp. 49-78. Allende: Alma en pena. Santiago, Chile: Demens \& Sapiens, 1998.

Orrego, Cristóbal. Las instrucciones del microondas. Santiago, Chile: Centro de Estudios Bicentenario, 2006.

"Estudio preliminar". En: Finnis, John. Ley natural y derechos naturales. Buenos Aires, Argentina: Abeledo-Perrot, 2000, pp. 9-32.

Orwell, George. "Prólogo: La libertad de prensa." En su: Rebelión en la granja. D.F., México: Editorial Porrúa, 2007.

Serrano, Sol. Universidad y nación. Chile en el siglo XIX. Santiago, Chile: Editorial Universitaria, 1994.

Sмiтh, Adam. La riqueza de las naciones. Buenos Aires, Argentina: Longseller, 2008.

Todorov, Tzvetan. La conquista de América. El problema del otro. D. F., México: Siglo XXI editores, 2007.

Urmson, James Opie. Interpretación de la filosofía moral de J. S. Mill. En: Foot, Philippa (ed.). Teorías sobre la ética. D.F., México: Fondo de Cultura Económica, 1994.

Vigo, Alejandro. Aristóteles. Una Introducción. Santiago, Chile: IES, 2007.

Von HaYeK, Friedrich. "La competencia como proceso de descubrimiento", en: Estudios Públicos, No 50, pp. 1-11.

Wittgenstein, Ludwig. Tractatus Logico-Philosophicus. Madrid, España: Tecnos, 2003. 